\title{
Andrew DAWSON, New Era - New Religions. Religious Transformation in Contemporary Brazil
}

Aldershot, Ashgate, 2007, 185 p.

\section{Véronique Altglas}

\section{CpenEdition}

Journals

Édition électronique

URL : http://journals.openedition.org/assr/21116

DOI : $10.4000 /$ assr.21116

ISSN : 1777-5825

Éditeur

Éditions de l'EHESS

Édition imprimée

Date de publication : 31 décembre 2009

Pagination : $75-342$

ISBN : 978-2-7132-2218-4

ISSN : 0335-5985

Référence électronique

Véronique Altglas, « Andrew dawson, New Era - New Religions. Religious Transformation in

Contemporary Brazil », Archives de sciences sociales des religions [En ligne], 148 | octobre-décembre 2009, document 148-40, mis en ligne le 19 mai 2009, consulté le 21 septembre 2020. URL : http:// journals.openedition.org/assr/21116; DOI : https://doi.org/10.4000/assr.21116

Ce document a été généré automatiquement le 21 septembre 2020.

(C) Archives de sciences sociales des religions 


\title{
Andrew DAWSON, New Era - New Religions. Religious Transformation in Contemporary Brazil
}

\author{
Aldershot, Ashgate, 2007, 185 p.
}

Véronique Altglas

\section{RÉFÉRENCE}

Andrew DAWSON, New Era - New Religions. Religious Transformation in Contemporary

Brazil, Aldershot, Ashgate, 2007, 185 p.

1 Voici un ouvrage qui intéressera aussi bien les chercheurs travaillant sur le Brésil que ceux qui de manière générale réfléchissent à la pluralisation du champ religieux dans les sociétés contemporaines. De ce point de vue, le Brésil est sans doute l'un des cas les plus fascinants, compte tenu de la diversité des religions en présence, de la créativité du champ religieux brésilien, et de la diffusion transnationale de ces innovations brésiliennes, dont l'Église Universelle du Royaume de Dieu n'est qu'un exemple. Ce sont donc de nouveaux mouvements et phénomènes religieux, brésiliens, qui sont ici présentés; l'accent est porté sur les dynamiques innovatrices qui participent de leur émergence et de leur diffusion, et sur les affinités de cette religiosité de la «nouvelle ère " avec la modernité.

2 L'ouvrage est structuré en cinq chapitres et débute par une utile introduction aux religions au Brésil. Le panorama est large et remonte au catholicisme populaire importé du Portugal, dont l'auteur souligne un super-naturalisme, une autonomie partielle visà-vis des structures ecclésiales, et un certain éclectisme. La diversification du champ religieux commence avec le protestantisme historique issu de l'immigration européenne et des missions nord-américaines, le candomblé né de l'héritage africain des esclaves, le spiritisme qui au Brésil se mêlera à des composantes afro-brésiliennes, catholiques et indigènes. Cette diversification se poursuit avec l'émergence de 
l'Umbanda, l'expansion des religions Ayahuasca hors des sociétés indigènes, l'importation des religions japonaises par voie migratoire, l'influence grandissante des pentecôtismes, et enfin avec ce que l'auteur appelle une religiosité «néo-ésotérique ». Cette religiosité "néo-ésotérique » (on pourra discuter de l'opportunité de ce terme) a commencé à se répandre de manière significative au milieu des années 1980. Elle puise dans un ésotérisme théosophique, rosicrucien et anthroposophique déjà présent au Brésil depuis la seconde moitié du XIX ${ }^{e}$ siècle, mais également dans des sources plus récentes, New Age et Nouveaux Mouvements Religieux issus de la contre-culture. Ce sont ces religiosités néo-ésotériques qui sont introduites dans le second chapitre de l'ouvrage, ce à partir de trois cas d'études: Templo da Boa Vontade, Vale do Amanhecer et Igreja Gnóstica do Brasil. Le chapitre qui suit couvre quant à lui les religions de type Ayahuasca. Celles-ci trouvent leur origine dans les sociétés indiennes qui vivent le long du fleuve Amazone - «ayahuasca » se réfèrant à la plante psychotrope utilisée par ces populations pour entrer en interaction avec le monde surnaturel. Ces consommations sont à présent pratiquées en dehors du contexte indien, de par l'émergence et la diffusion de trois religions brésiliennes nouvelles, Barquinha, União do Vegetal et le Santo Daime. Celles-ci ont su intégrer des éléments afro-brésiliens et médiumniques et, en milieu urbain, elles s'articulent à présent à un répertoire néo-shamanique et à une écospiritualité. Le quatrième chapitre se concentre sur les aspects discursifs spécifiques de cette nouvelle ère. Dawson distingue trois motifs : une perspective holiste, un ethos individualiste, et un pragmatisme vis-à-vis des connaissances et techniques offertes pour atteindre un bien-être. Ces motifs sont illustrés à partir des cours de la « Nouvelle Gnose » diffusée par l'Igreja Gnóstica do Brasil; la diffusion de ce discours holiste, individualiste et pragmatique est également approchée par l'analyse du succès des livres de Paulo Coelho et Leonardo Boff. Pour terminer, le dernier chapitre met en perspective la "religiosité de la nouvelle ère ", en soulignant la manière dont celle-ci reflète les conditions de la vie sociale moderne et urbaine. L'auteur considère trois facteurs au principe de cette pluralisation du champ religieux brésilien : l'émergence de nouveaux mouvements, l'individualisme qui permet une dynamique de choix, et des processus macro-sociaux tels la sécularisation de l'État brésilien, l'impact d'une industrialisation et d'une urbanisation rapide, la globalisation, et l'apparition d'un "marché religieux». Si cette approche confond quelque peu causes et effets, plus intéressant, nous semble-t-il, est la manière dont ces aspects de la modernité s'articulent avec des particularités du champ religieux brésilien. Il s'agit d'une part de ce que l'auteur appelle l'éthos religieux brésilien qui a développé une vision du monde peuplé de forces tant physiques que spirituelles, et unit par là spiritisme, religions afrobrésiliennes et catholicisme populaire brésilien ; et d'autre part une diversité religieuse qui dès la colonisation a favorisé des porosités et des interpénétrations entre les religions en présence (pp. 159-160).

3 Ce livre est précieux en ce qu'il introduit des phénomènes religieux peu décrits et étudiés hors du Brésil. Il synthétise efficacement les divers travaux sur le sujet et les rend ainsi accessibles aux non-lusophones. La sociologie de la religion brésilienne est riche et mérite d'être mieux connue - de ce point de vue, la bibliographie en fin d'ouvrage est fort utile et constitue un bon outil pour aborder le champ religieux brésilien contemporain. En outre, il faut reconnaître la qualité du travail empirique présenté ici : l'histoire, les rites et croyances de chaque cas d'études sont présentés avec détail, mais surtout la description des entrecroisements de répertoires religieux, de la diversification interne de ces mouvements lorsqu'ils se diffusent dans de 
nouveaux milieux sociaux sont particulièrement intéressants. On regrettera simplement, aux vues de la richesse des données ici présentées, l'absence d'une réflexion plus générale qui pourrait contribuer au débat sur le syncrétisme, le bricolage et l'hybridité. 